\title{
Multifunction Sandwich Structure Based on Diffusible 2- Chloroethylamine for High-Efficiency and Stable Tin-Lead Mixed Perovskite Solar Cells
}

Xuehao Zhang, a Yang Hao,a* Shiqi Lia, Jingkun Rena, Yukun Wu, a Qinjun Suna, Yanxia

Cui,a Yuying Haoa*

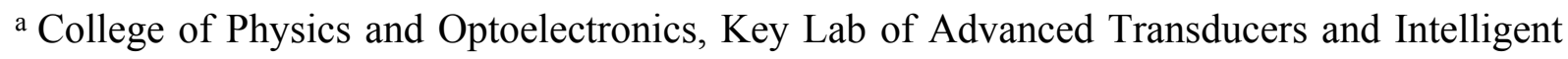
Control System, Taiyuan University of Technology, Taiyuan 030024, China.

*Corresponding author. E-mail address: haoyang@tyut.edu.cn, haoyuying@tyut.edu.cn
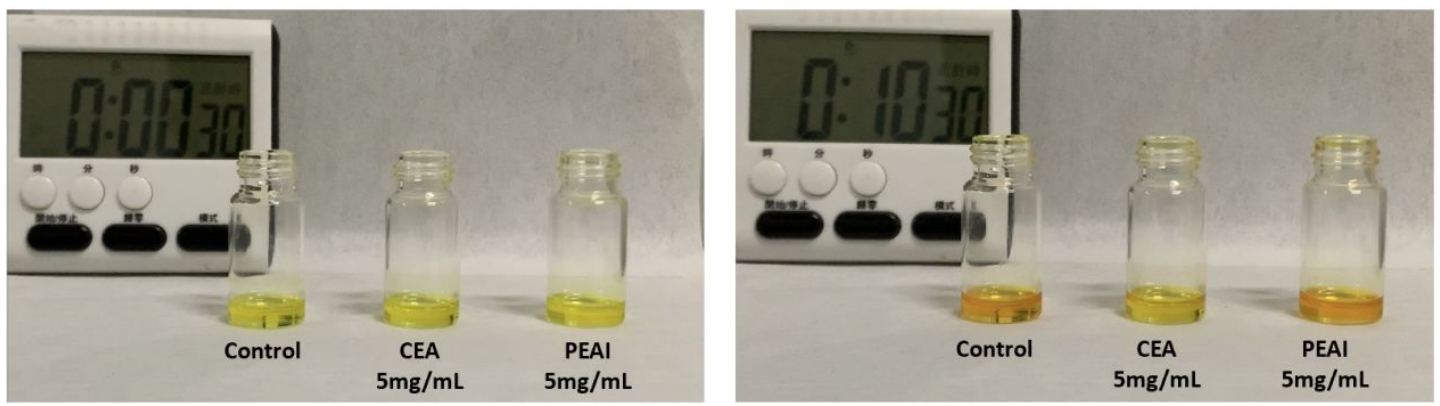

Figure S1. The color changing of tin-lead mixed precursor solution without and with CEA, PEAI additive exposed to air for 10 minutes. 


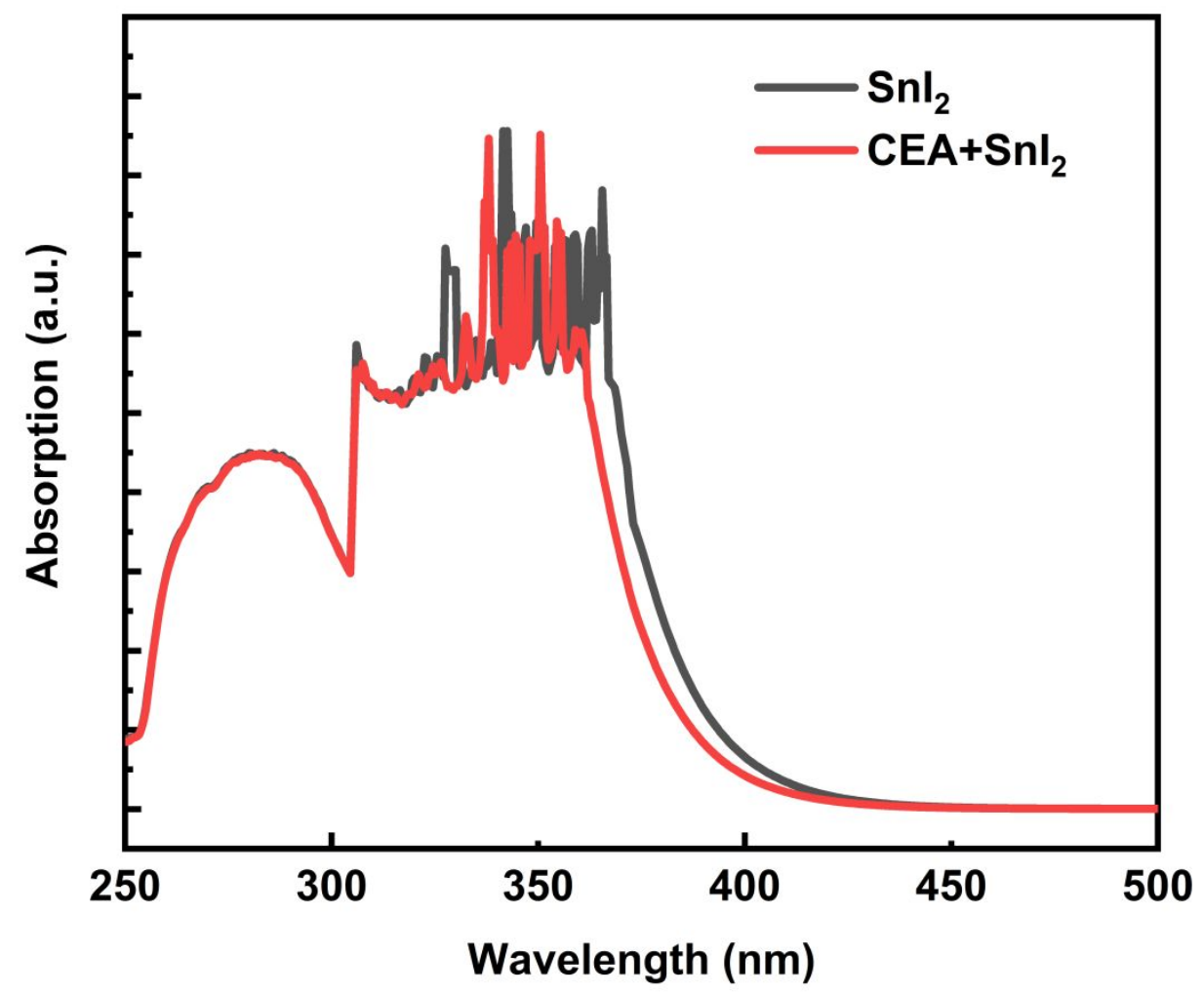

Figure S2. UV-vis absorption spectra of the $\mathrm{SnI}_{2}$ solution dissolved in DMSO with CEA as additive.

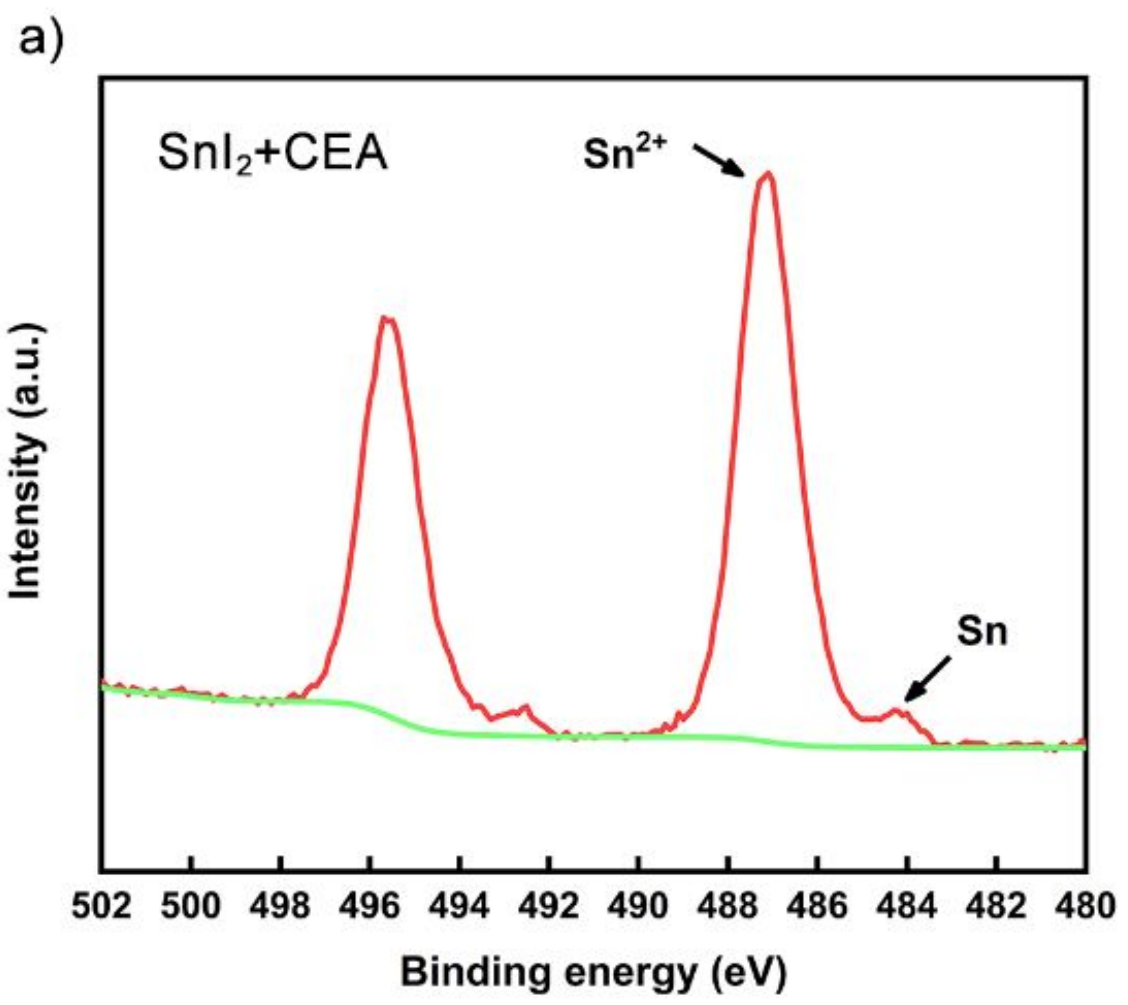




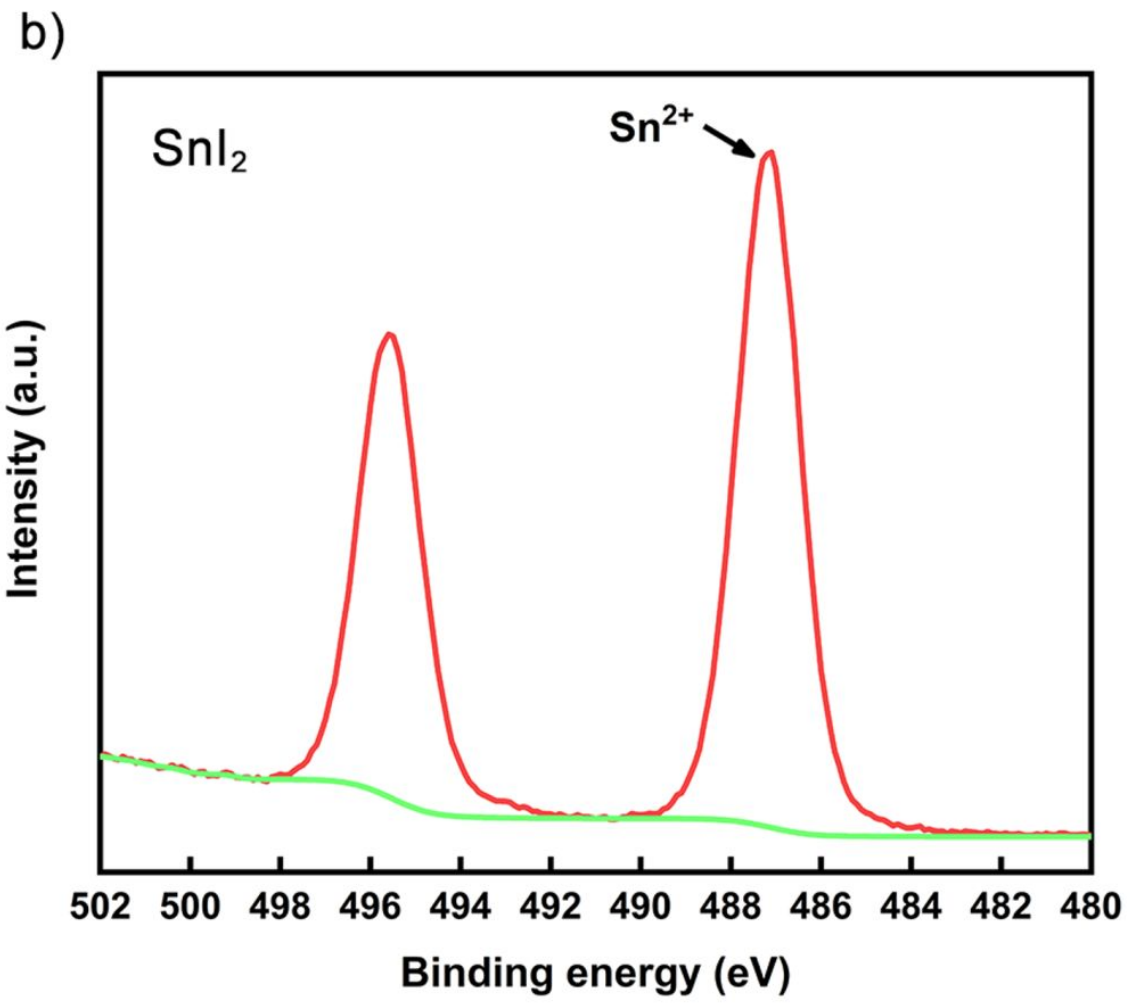

Figure S3. The corresponding XPS Sn 3d spectra for powder of $\mathrm{SnI}_{2}+\mathrm{CEA}(\mathrm{a})$ and $\mathrm{SnI}_{2}(\mathrm{~b})$. The extra peak for $\mathrm{SnI}_{2}+\mathrm{CEA}$ sample indicates the signal of $\mathrm{Sn}(0)$.

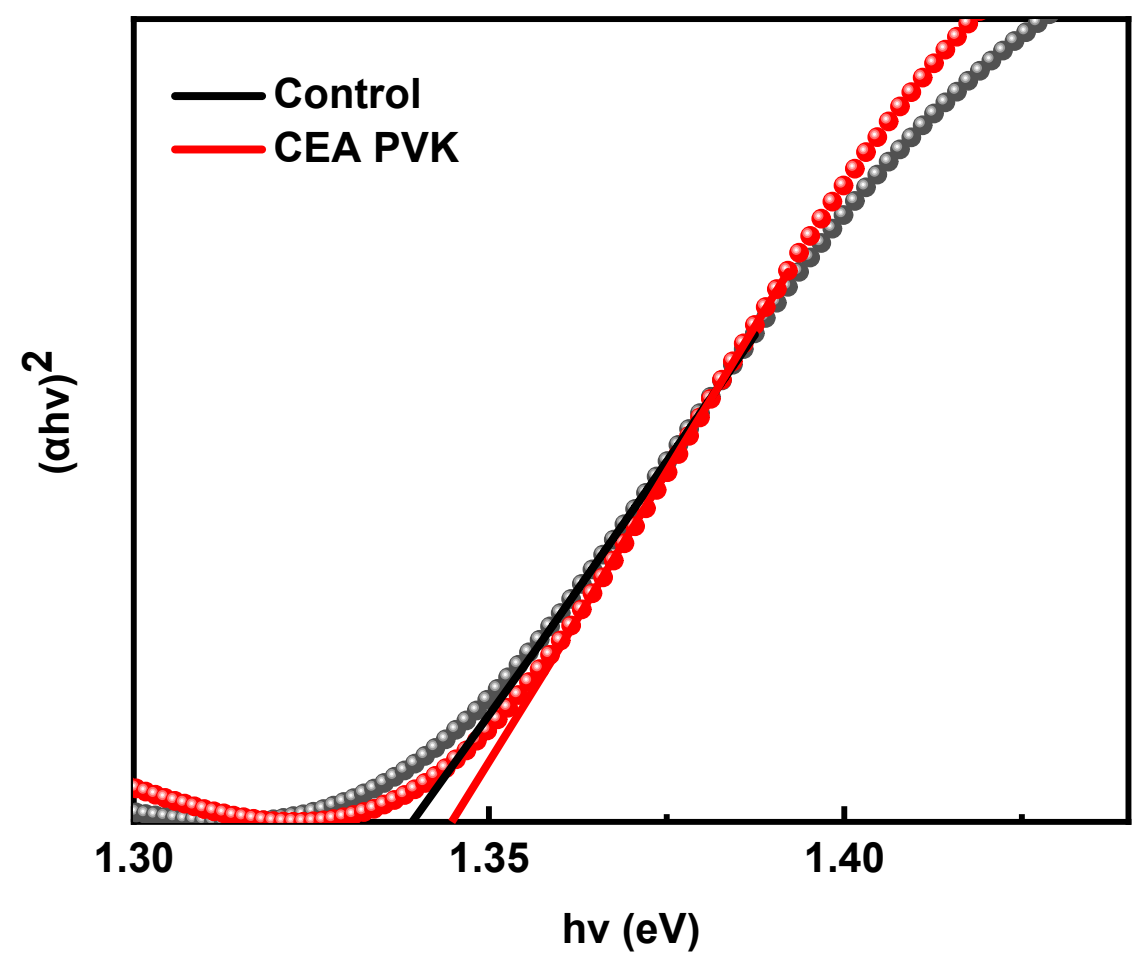

Figure S4. Tauc plot of UV-Vis-NIR absorption spectra of Control (dark) and D-CEA-PVK (red) films. 


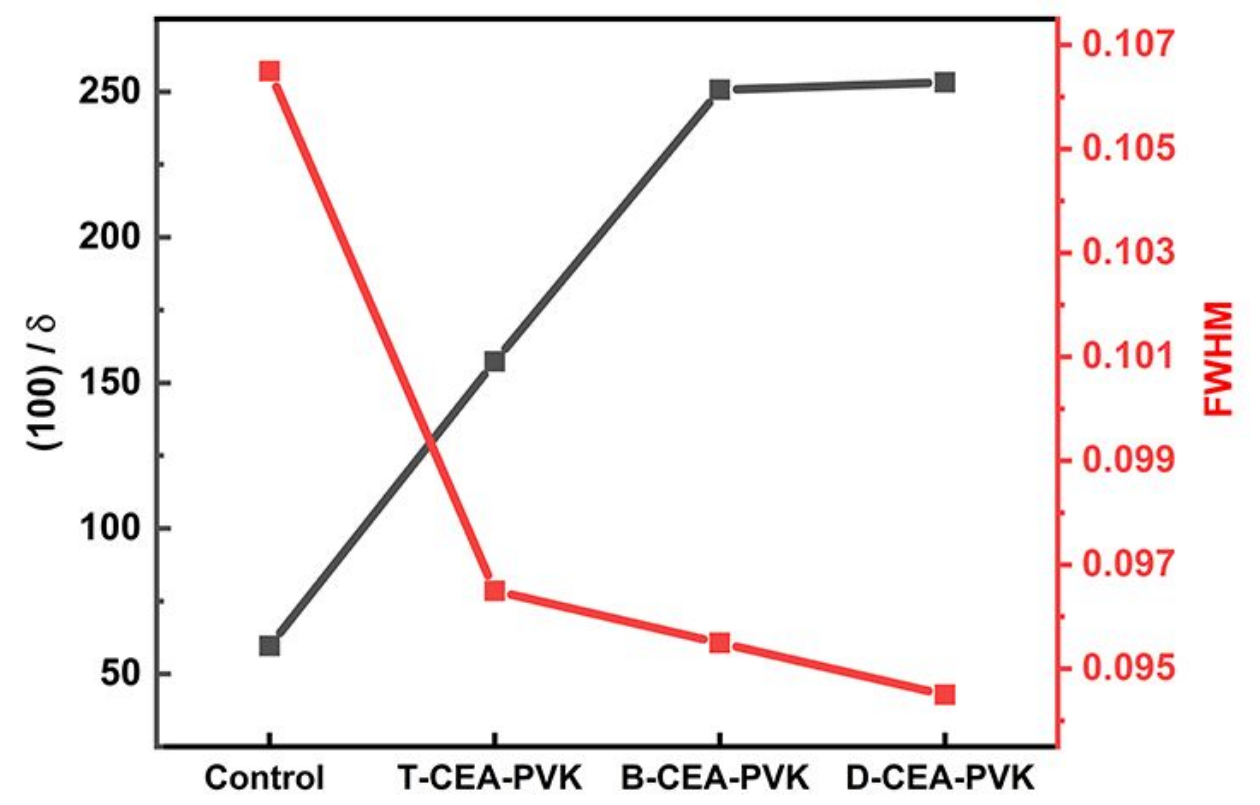

Figure S5. The full-width-at-half-maximum (FWHM) of (100) peak and corresponding (100)/( $\left.\mathrm{PbI}_{2} / \mathrm{SnI}_{2}\right)$ peak intensity ratios for Control and CEA modified films. 


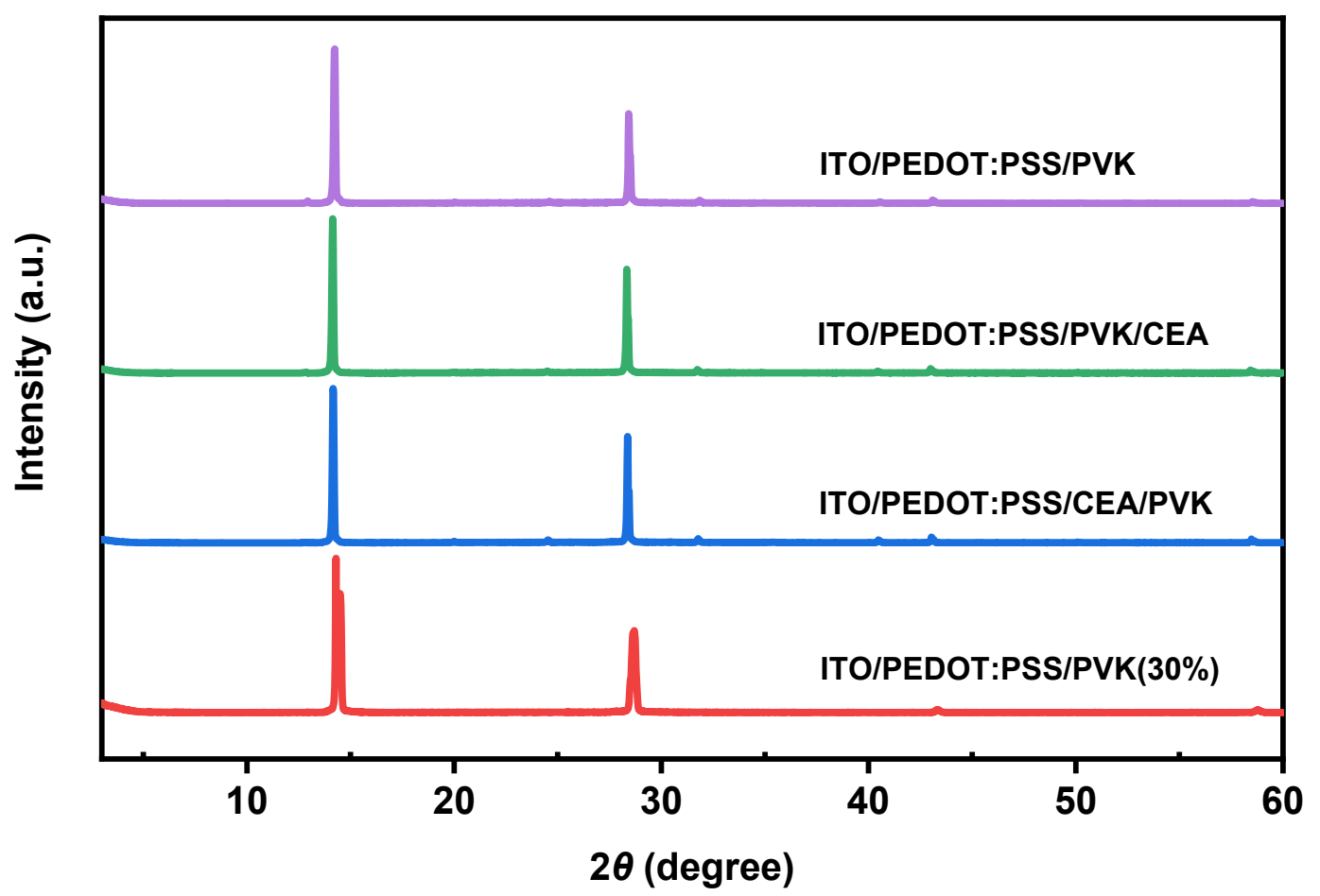

Figure S6. XRD patterns with normalized intensities of the B-CEA-PVK (blue), the T-CEA-PVK (green), PVK made with the CEA additive with $30 \mathrm{~mol} \%$ (red), and control (purple).
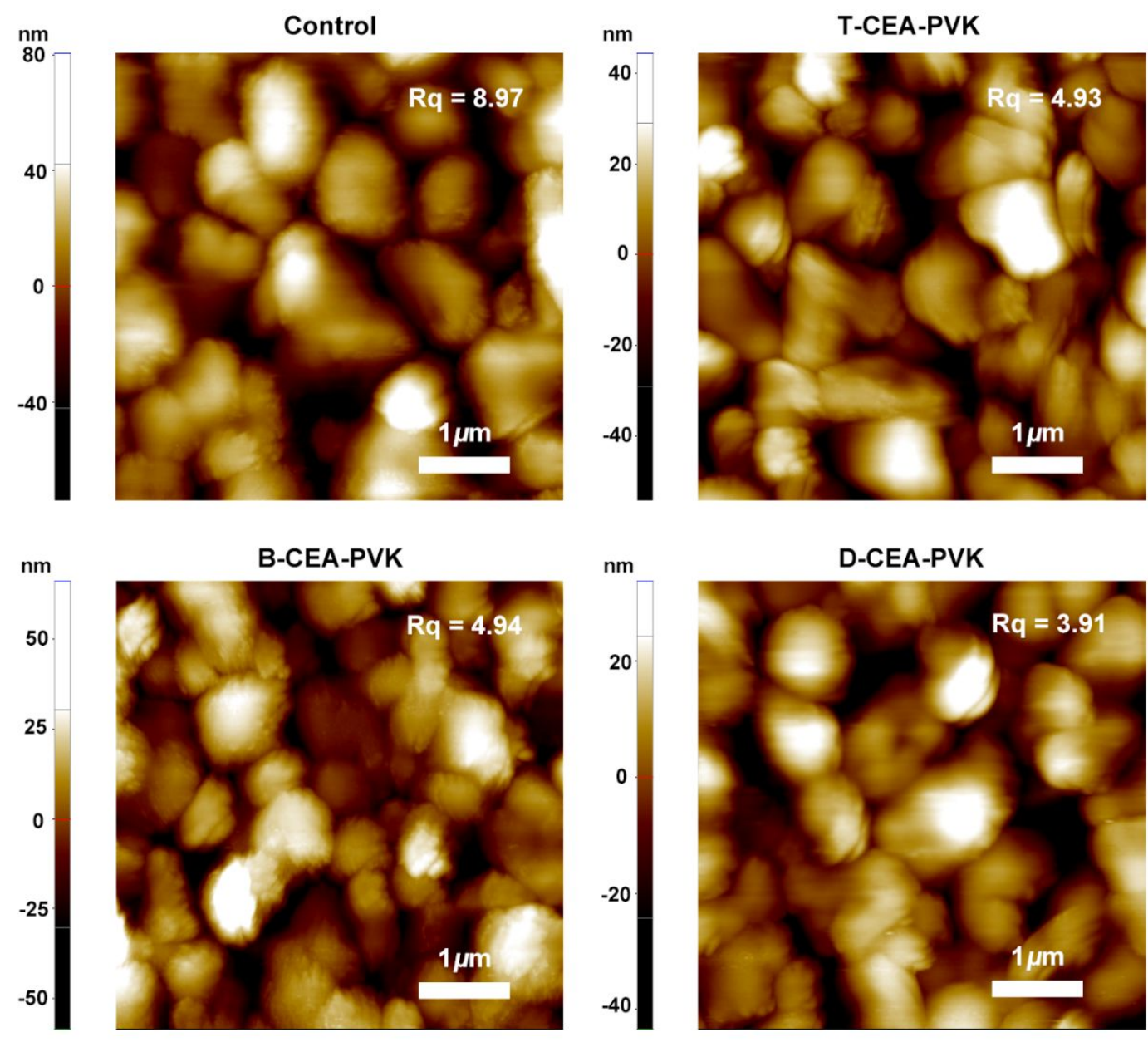
Figure S7. AFM height images $(5 \mu \mathrm{m} \times 5 \mu \mathrm{m})$ of Control, T-CEA-PVK, B-CEA-PVK, and D-CEA-PVK perovskite films.

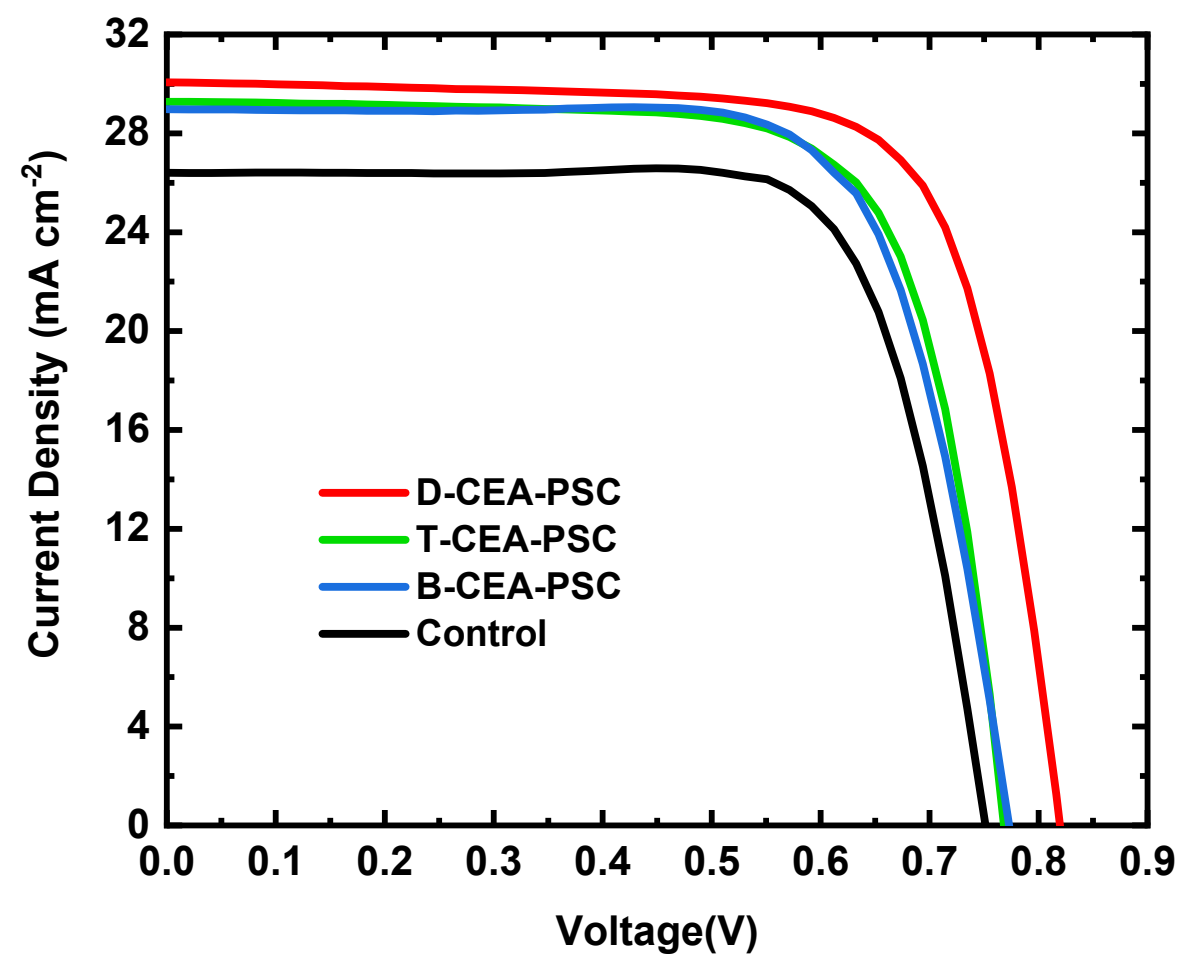

Figure S8. The $J-V$ curves of Control, B-CEA-PSCs, T-CEA-PSCs, and D-CEA-PSCs with an optimized CEA concentration of $4 \mathrm{mg} / \mathrm{mL}$ in IPA solvent including little DMF. 


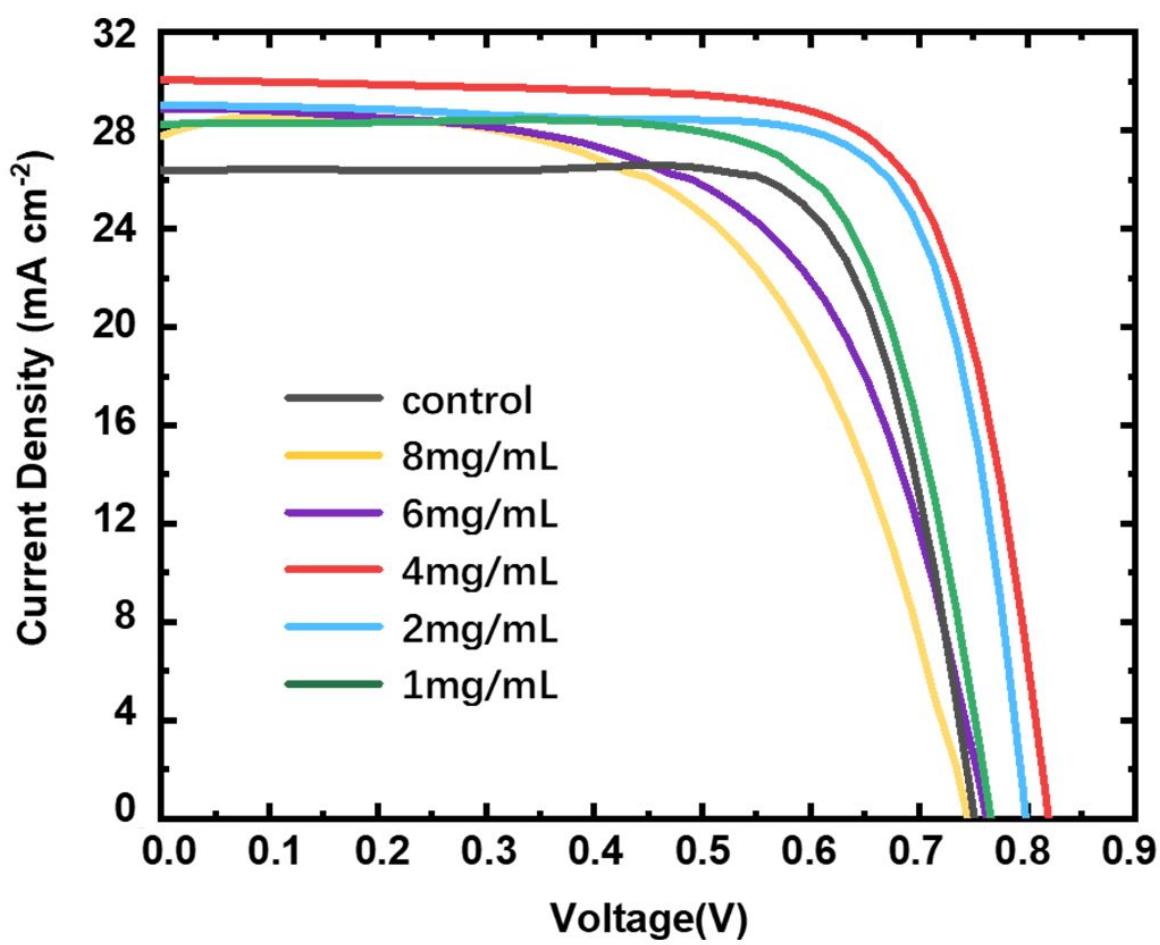

Figure S9. The $J-V$ curves of D-CEA-PSCs with CEA of different concentration.

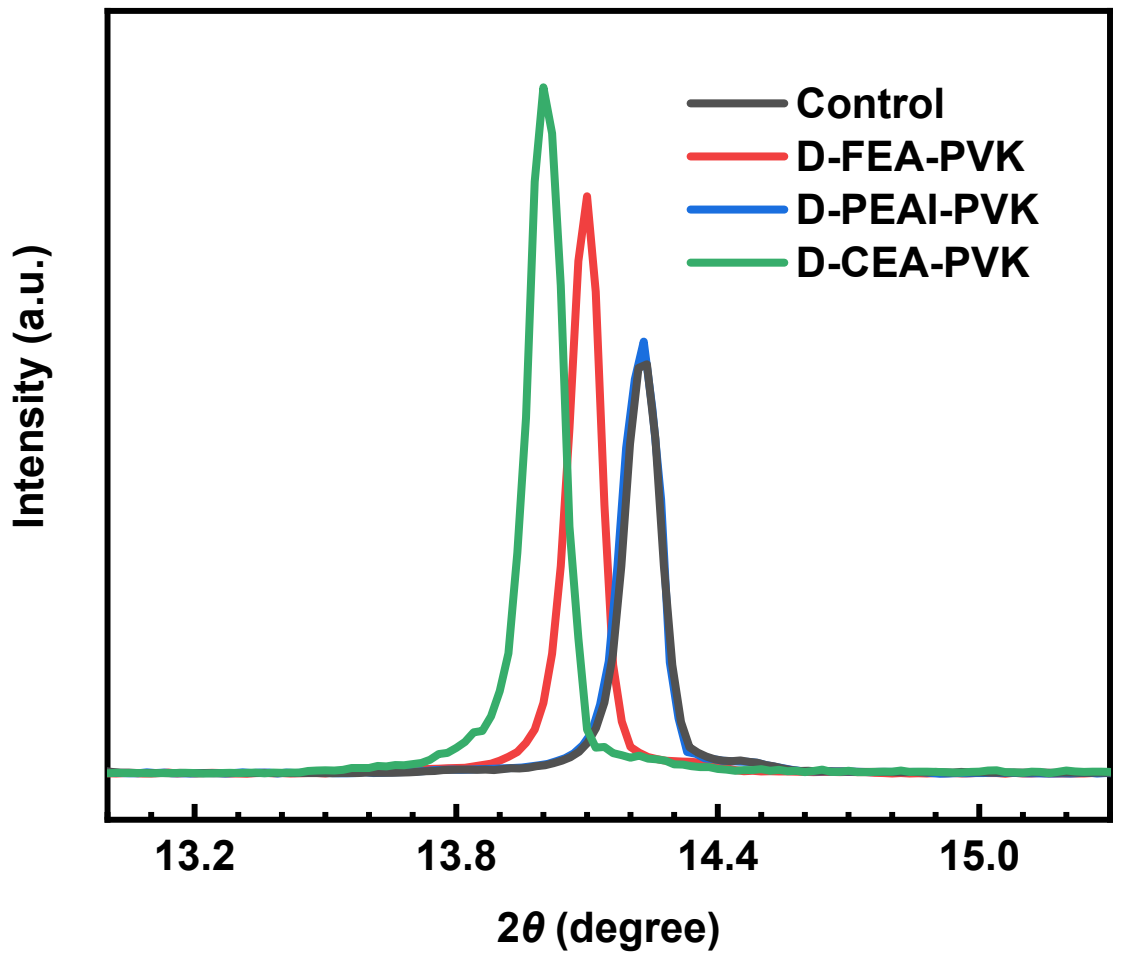

Figure S10. The close-up XRD patterns of the (100) peak with absolute intensities for Control and CEA, FEA, and PEAI modified perovskites. 


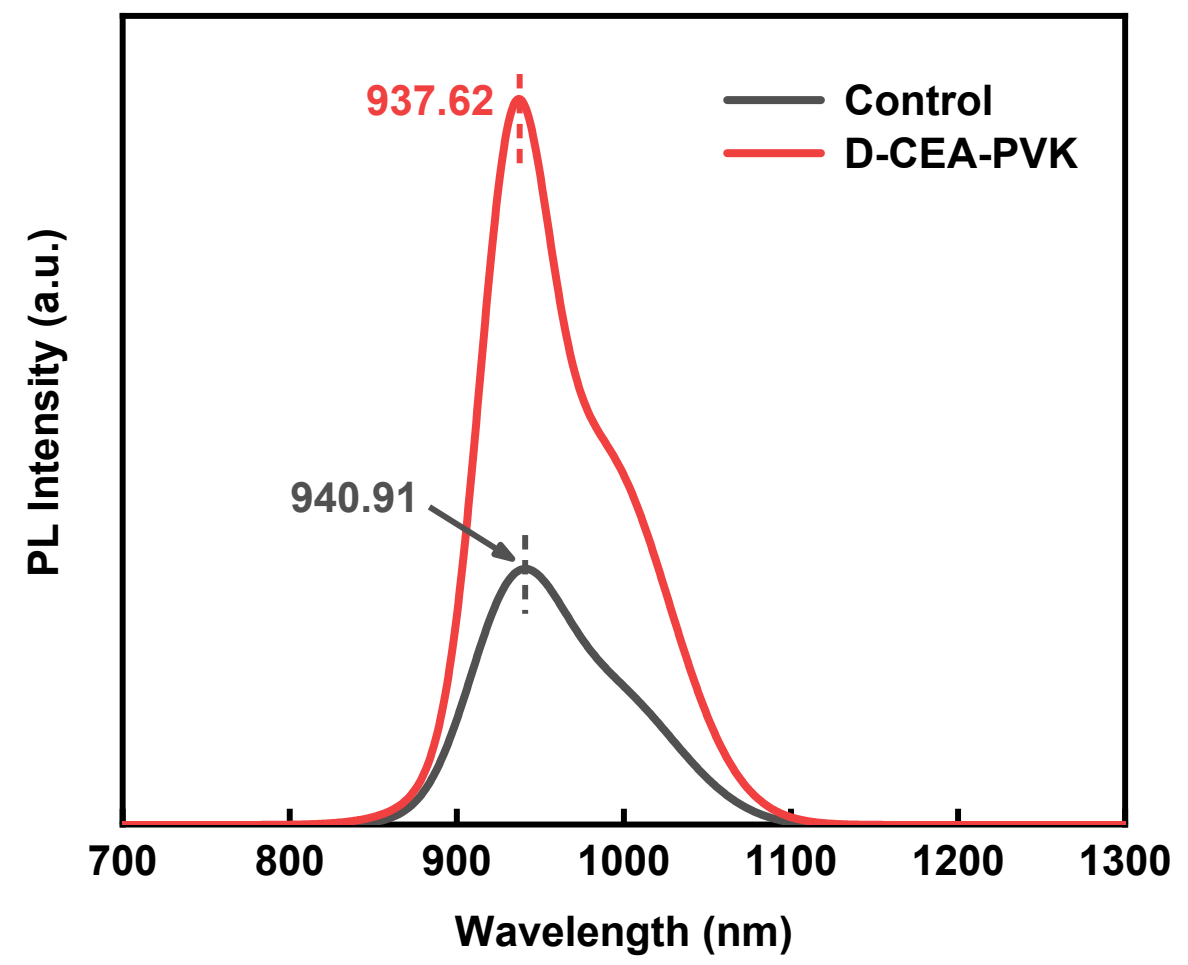

Figure S11. The steady state PL intensity of Control and D-CEA-PVK.

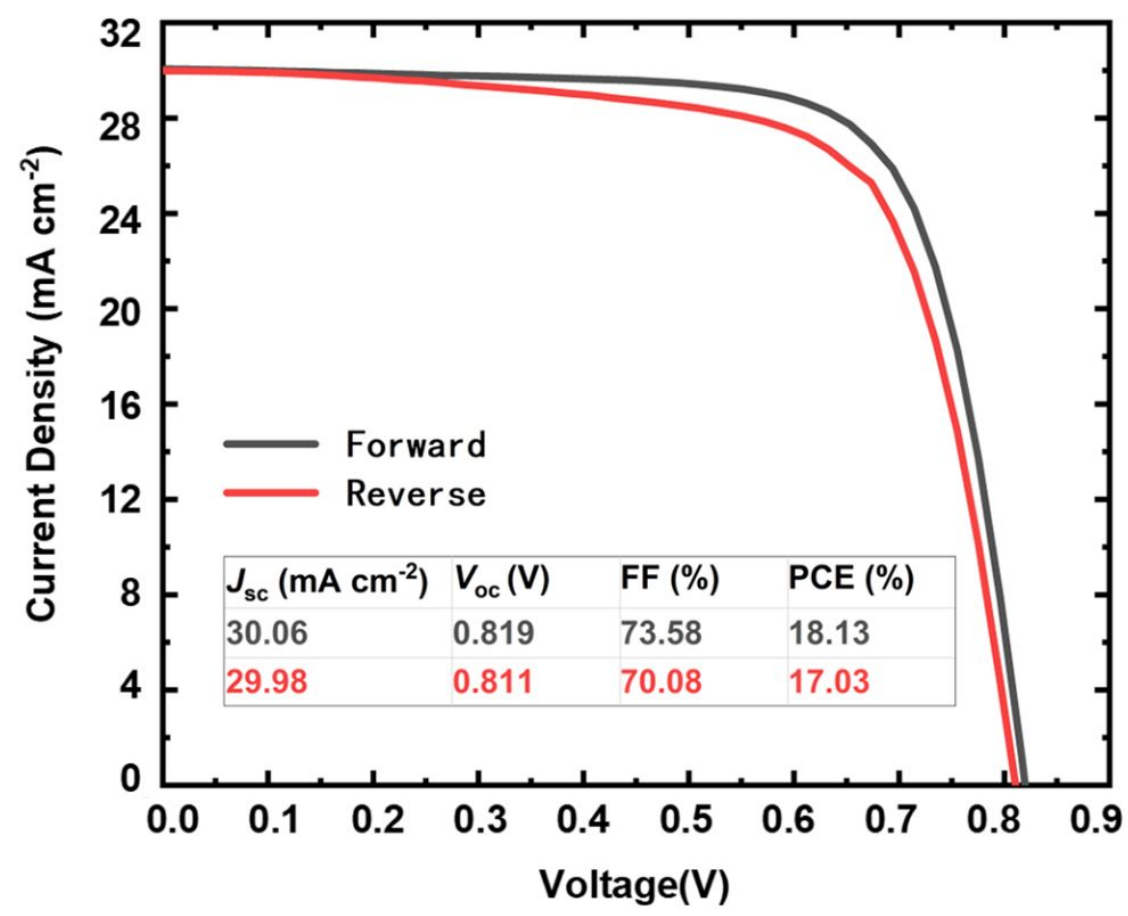

Figure S12. $J-V$ curves of the best-performing PSC based CEA/Perovskite/CEA sandwich structure, inset table was the corresponding performance data. 


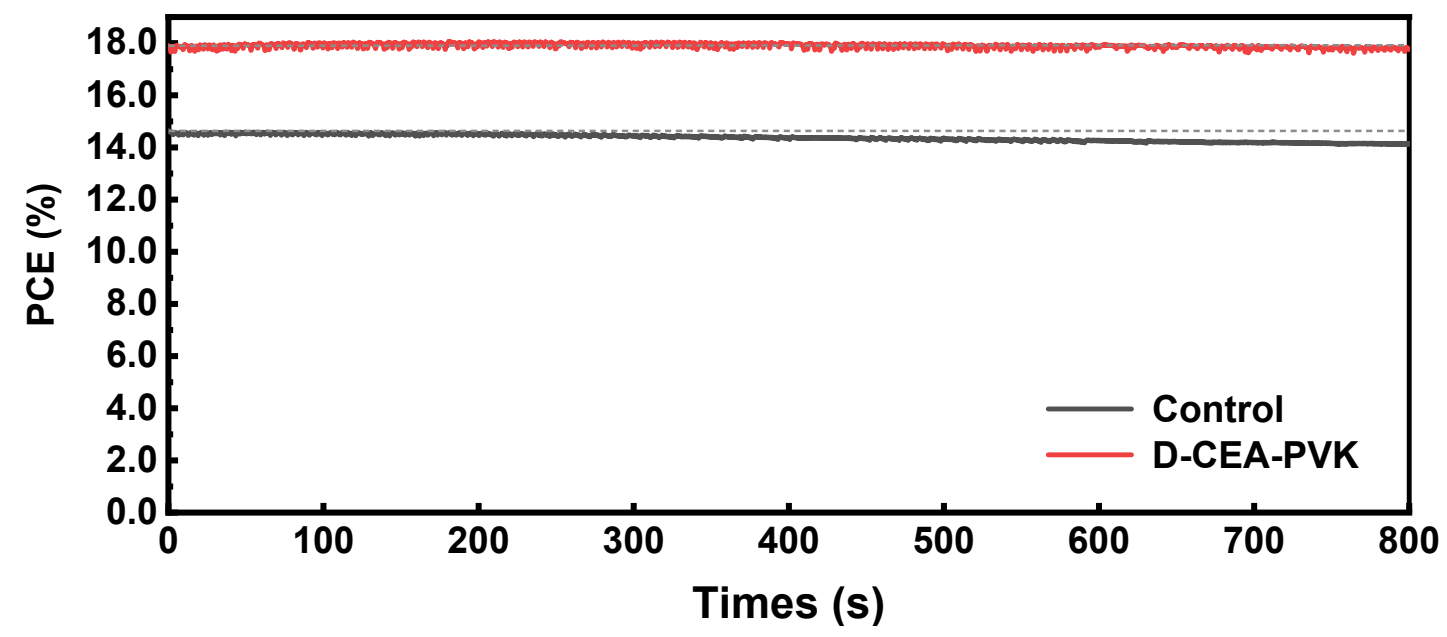

Figure S13. MPP tracking of the tin-lead mixed PSC with and without CEA measured in the glove box under simulated AM 1.5G solar illumination.

Table S1. The statistic photovoltaic parameters for the D-CEA-PSCs with CEA of variety concentration.

\begin{tabular}{cccccc}
\hline variation & $J_{\mathrm{sc}}\left(\mathrm{mA} \mathrm{cm}^{-2}\right)$ & $V_{\mathrm{oc}}(\mathrm{V})$ & $\mathrm{FF}(\%)$ & $\begin{array}{c}\text { Average } \\
\mathrm{PCE}(\%)\end{array}$ & Best PCE $(\%)$ \\
\hline Control & $26.47 \pm 0.44$ & $0.741 \pm 0.009$ & $73.41 \pm 1.83$ & $14.41 \pm 0.37$ & 14.83 \\
$8 \mathrm{mg} / \mathrm{mL}$ & $28.16 \pm 0.56$ & $0.760 \pm 0.006$ & $62.59 \pm 1.78$ & $13.39 \pm 0.14$ & 13.59 \\
$6 \mathrm{mg} / \mathrm{mL}$ & $28.38 \pm 0.29$ & $0.777 \pm 0.003$ & $69.02 \pm 1.97$ & $15.22 \pm 0.29$ & 15.58 \\
$4 \mathrm{mg} / \mathrm{mL}$ & $29.63 \pm 0.53$ & $0.812 \pm 0.008$ & $73.80 \pm 1.4$ & $17.75 \pm 0.27$ & 18.13 \\
$2 \mathrm{mg} / \mathrm{mL}$ & $28.23 \pm 0.41$ & $0.793 \pm 0.006$ & $73.56 \pm 1.82$ & $16.48 \pm 0.41$ & 17.15 \\
$1 \mathrm{mg} / \mathrm{mL}$ & $27.95 \pm 0.88$ & $0.754 \pm 0.013$ & $72.21 \pm 3.09$ & $15.20 \pm 0.36$ & 15.67 \\
\hline
\end{tabular}

